\title{
IMPROVING PRODUCTION EFFICIENCY OF LARGE SIZE MOLDS AS A RESULT OF INNOVATIVE QUALITY CONTROL PROCESS
}

doi:10.2478/mape-2018-0058

Date of submission of the article to the Editor: 03/2018

Date of acceptance of the article by the Editor: 06/2018

MAPE 2018, volume 1, issue 1, pp. 457-465

Assoc. Prof. Beata Skowron-Grabowska, PhD.

Jarosław Jasiński, PhD., Eng.

Anna Jasińska, Msc., Eng.

Czestochowa University of Technology, Poland

Doc. Ing. Pavel Beňo, PhD.

Technical University Zvolen, Slovak Republic

Prof. Ing. Ján Paško, CSc.

Technical University Kosice, Slovak Republic

\begin{abstract}
One of the basic elements of the technological chain of manufacturing products in the European Union is the metal processing sector, which is one of the dynamically developing industries. An important department in the aforementioned sector is the production of unconventional, large-size injection molds and tools weighing more than 10 tons. Very often large-size components in the production process must be precisely checked and subjected to appropriate corrective actions at the quality control stage, in order to avoid non-compliance with customer requirements, and thus increased costs related to reducing production efficiency, logistics of large-size elements from the customer back to the manufacturer of the mold in order to correct it, and also complaints of the final product connected with dimensional changes and surface defects in the casting process. This paper presents a case study of the implementation of the innovative quality control process to verify the production of large-size molds for aluminum high pressure casting with the spotting press machine, allowing for product quality improvement. The introduction of the innovative press for spotting molds to the quality control stage also leads to the improvement of production efficiency, which was confirmed by the results of an increase of the OEE coefficient in the entire production process. In addition, a significant reduction in the production time of products was achieved, and the cost of the mold production process was lowered.
\end{abstract}

Keywords: spotting process, quality control, large size molds, OEE index

\section{INTRODUCTION}

The metal industry, due to the support for many production sectors, includes a vast majority of European cities and regions while simultaneously belonging to the most expansive industrial sectors in Poland. In spite of the fact that it concentrates many large enterprises, its main driving force are the companies of the SME sector operating as subcontractors in the EU supply chain. It is also one of the few sectors whose structure is characterized by high flexibility and innovativeness. The development of innovation in the metal sector is to a large extent related to the implementation of automation systems and modern infrastructure for production processes (Skrzypek and Dąbrowski, 2017; Schöne et al., 2010; Stasiak-Betlejewska and Ulewicz, 2016). Within the framework of trends that prevail on the global market, directions of development of a given industry sector as well as standards and requirements for the manufactured elements are determined, which also applies to the aforementioned sector. According to the data, the field of metalworking is the main branch of development of the EU economy, which accounts for $10 \%$ of the value added to the manufacturing industry and for 
$7,5 \%$ of industrial production. This sector is one of the largest employers in the industry of the European Union, where SMEs (small and medium-sized enterprises) have the greatest share (The "invisible" sector of European industry - now in the center of attention). Significant development of the above-mentioned sector within the countries of the European Union is connected with the implementation of the innovative production infrastructure, but also with the equipment of the quality control department and the research and development (R\&D) department of companies that allow for the streamlining of production processes and improving the quality of the product. As a result, it affects the competitiveness of enterprises and an increase in partnership between the suppliers of semi-finished products, manufacturers and the final users of the product. The development of the metal sector is in line with the current trends in the implementation of advanced production processes using modern technologies, including, among others, manufacturing and machining of components from special materials such as elements of engines, gears and complete transmission gears, as well as large-size components such as rotor hubs of wind farms, matrices and molds for the high pressure die- casting of light alloys etc. (Haddag et al., 2016; Shimizu et al., 2001; Onozuka et al., 2013; Nowicka-Skowron and Ulewicz, 2015). It should be emphasized that an important stage of the production process of each large-size component is quality control, as a result of which basic parameters of the manufactured product and, above all, compliance with the customer's requirements are checked. Along with an increase in the complexity of the shape of components, their dimensions and weight and the advancement of manufacturing processes, quality control is a difficult stage to performing conditions of the unitary production of large-size tools. On the other hand, the development of the market of specialist products requires that customers have technologically advanced devices for quality control processes. Production processes, associated with the manufacture of large-size molds with a weight of, say, 30 tons, are conditioned, among others, by the possibility of precise verification and adjustment of the mold after the machining process in order to achieve the highest possible manufacturing quality (Hamrol and Mantura, 2005; Skotnicka-Zasadzien et al., 2017; Zasadzien and Midor, 2015). Therefore, in both the quality control departments and in the R\&D departments of companies which manufacture large-size elements, specialist innovative tools (both measuring and verifying the correctness of the manufacture of molds) need to be used. One of the operations used to check the aforementioned properties of large-sized components is spotting, i.e. a process carried out with the use of a device called a spotting press, consisting in the adjustment of the movable and fixed part of the mold, and in case of slide molds - all the elements of the mold. This operation is used to determine the linearity, collision of the fixed and movable part and the leak-tightness of the mold, in order to perform any correction or removal of the material allowance to obtain a cast element with high quality parameters, in compliance with the client's requirements (Figure 1) (Hashikawa et al., 2016).

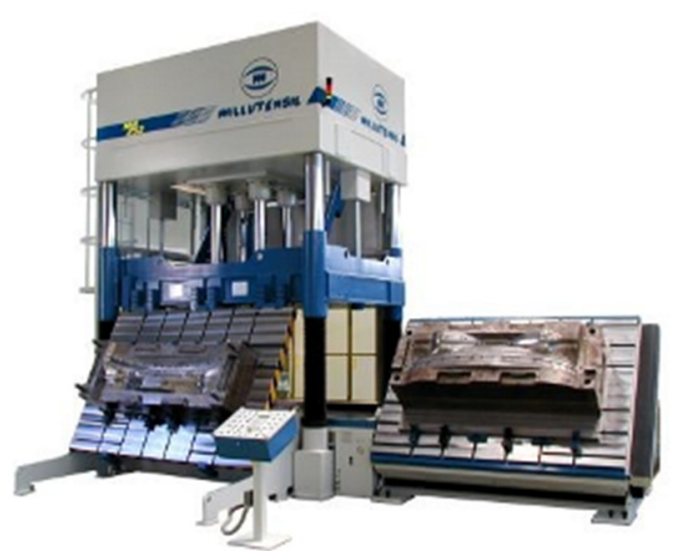

Fig. 1. Spotting press used for large-size molds quality control process Source: Milutensil Company 2015 Lower mold-testing costs with spotting press, Moldmaker 
In order to present the effect of implementation of innovative technologies in the quality control production stage associated with the manufacture of molds of more than 15 tons (the so called large-size molds), the authors have chosen the spotting technique which gives advantageous results in the improvement of the efficiency of the production process. Implementing the spotting press allows enterprises to make more complicated molds, improve the effectiveness of production and quality control, or to carry out studies and R\&D works on the standardization of the manufacture of foundry molds for many industries, which will be presented in the paper.

\section{TECHNOLOGICAL PROBLEM}

So far, one of the main limitations of enterprises in the metal sector is the problem of making large-size molds weighing over 15 tons. The development of the metalworking sector enforces a substantial increase in the demand for increasingly complex products manufactured using the instrumentation of tools e.g. for pressure die-casting technology, which satisfies new requirements of the clients. Molds are more often complicated, so that the checking process is also difficult to realize and so is the role of a spotting press to validate a mold. In this case, it is particularly important to be able to manufacture large-size molds for pressure die-casting of light alloys, i.e. molds of up to 30 tons used for the production of complex and operationally durable parts in the automotive industry, aerospace etc. The projects of complex molds of more than 15 tons, due to their weight, dimensions and degree of the structure complexity, required the proper technical preparation and development of the specific manufacturing technology and, above all, the possibility of verification of the adopted technical assumptions so that the final product meets the customer requirements while maintaining the level of profitability. The extension and technical upgrade of the research and development (R\&D) department into a modern press for precise spotting of large-size molds thus affects the improvement of the competitiveness of the enterprise which manufactures large-size molds. The introduction of a modern press allows first of all to adapt large-size molds for pressure die-casting to current market requirements, as well as to carry out specialist research related to the optimization of difficult technological operations within the scope of manufacturing the above mentioned molds (Łuszczak and Dańko, 2013; Lynch et al., 2010). The press is used, among other things, to determine the correctness of geometrical parameters by an imprint of the plastic mass, to check the leak tightness under the conditions of the applied pressure and temperature during the operation of the mold after installation on the casting machine. During spotting, you can also easily check material surplus on molds and slides after processing, which to a large extent allows to optimize parameters of the CNC machining or the electrical discharge machining (EDM) (Schmidt and Schauer, 1994; Nunes et al., 2017; SarmientoMeridaet al., 2018, Zorawski et al., 2008).

MoldmakerAnother important advantage is the possibility to study the impact of the size of surplus components of the mold's prototype on the moving of movable parts against each other and to study the effect of the mold's temperature and the assumed pressure of the liquid material injection on the tightness of the mold's prototype. In addition, it is important to be able to perform the final control of the wall thickness as well as to finish and perfect the surface of the obtained mold prototype. With the precision spotting press, the checking of high-quality large size molds can be completed easily and quickly because spotting presses have high repeatability and accuracy. Dies parallelism control system accurately brings the two halves together. This technology features four electronic measurement devices (encoders), which continuously check the press' upper plate position and parallelism while comparing it with the lower part (Figure 2). 


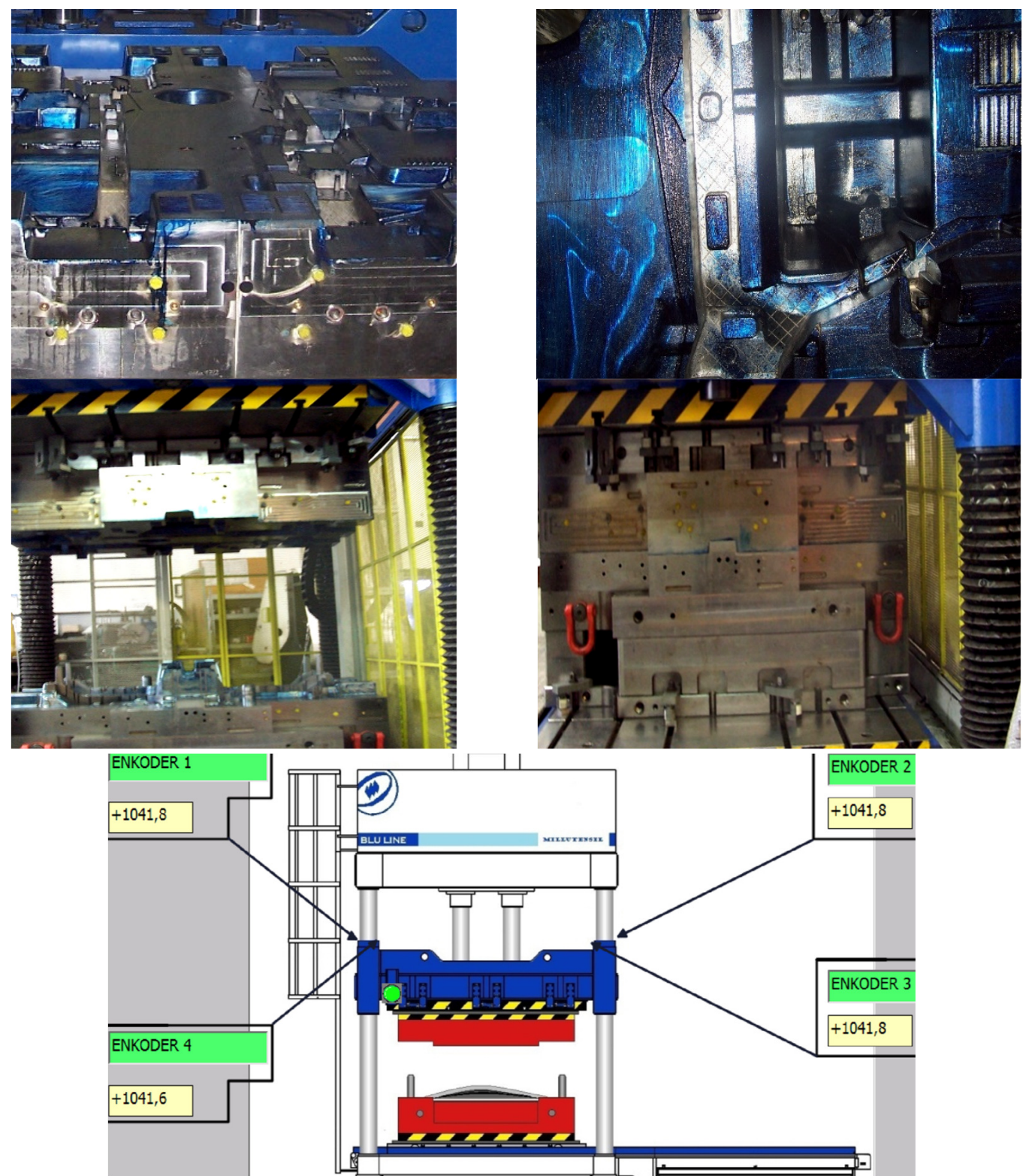

Fig. 2. View of the implementation of the spotting process of fixed and movable parts of the large-size mold (30 tons) to manufacture components using the pressure die-casting technique

Source: Milutensil Company 2015 Lower mold-testing costs with spotting press,

Encoders are located diagonally in the four external corners of the upper plate with the columns and the measurements are displayed on a touch panel for the entire stroke. If the preset limit parameters are exceeded (i.e. when hydraulic cylinders are retracted) the stroke's movement is immediately disabled and the error is displayed (Malosio and Kauzlarich, 2015).

\section{INNOVATIVE QUALITY CONTROL OF THE LARGE SIZE MOLDS - CASE STUDY}

An important objective of the study was to perform leak tightness tests in the process of closing the mold at the pressure required by the customer, in order to possibly correct and adjust the areas, adequately to the pressure applied in a given area. An additional, significant assumption while implementing the large-size mold production technology was the maximum reduction of the order execution time by about $25-30 \%$ in comparison with the current production of medium-sized molds - up to 15 tons, as well as eliminating the stage of using the spotting process services performed in external companies, not available in the country, which 
considerably extended the lead time. An indicator to achieve in this case was the time from taking the order to the final acceptance of the mold manufactured by the ordering party, after technological tests in the foundry. Another indicator is the time of the very spotting stage along with the application of dimensional adjustments and the stage of the so-called superfinishing, corrective grinding directly on the spotting press. The key objectives for the implementation of the die spotting tests were the maximum reduction of material allowance, already at the stage of manufacturing the mold, and shortening the time of the possible correction of shapes and the dimensions of the mold, as a result of the accelerated spotting stage with the press. An additional objective was to make corrections to the technical designs in places of possible surpluses or losses of materials and in places with the greatest operational durability requirements, e.g. in the area of the gating system, with their transfer directly to the production stage of a large-size mold. The accomplishment of the formulated overarching objective of the investigations was associated with the development and technical upgrading of the research and development (R\&D) department with the only one in Poland modern die spotting press machine for large-size molds This is related to the prediction of material surplus reduction in individual blocks of the mold already at the stage of manufacturing the semi-finished product. An important objective of this research study was also to perform leak tightness tests in the process of closing the mold at the pressure required by the customer, in order to possibly correct and adjust the areas, adequately to the pressure applied in a given area. Another indicator is also the time of the spotting stage together with the application of dimensional adjustments and the phase of the so-called superfinishing, corrective grinding directly on the spotting press. The key assumption for the implementation of the spotting tests was the maximum reduction of material allowance during the mold production, already at the stage of manufacturing it, and shortening the time of the possible correction of the shapes and dimensions of the mold, as a result of the accelerated die spotting stage with the press. Additional objectives were to make corrections to technical designs in places where potential surpluses or losses of materials might appear and in places with the highest requirements of operational durability, e.g. within the area of the gating system, with their transfer directly to the stage of production of the large-size mold (Figure 3.)

The final stage of the mold production is the re-checking of the mold's collision using the spotting press. Then, leak tightness tests and injection tests are performed on the casting machine at the ordering party. After accepting the shapes of the cast, the mold is subject to formal acceptance as well as the acceptance of the terms of the contract both by the ordering party and the contractor of the mold.

The spotting press implemented in the R\&D section, allowed to realize following operations:

- shortening of the time of mold production process with the necessary multiple repetition of fitting stages,

- closing of molds during the operation of fitting and leveling the surface between each block of the mold,

- rotation of the upper part of the mold to the position required by the operator, specified at the mold assembling,

- modelling and simulation of casting injection process with using wax components to investigate the surface of the casting element, its complementarity and defects (e.g. porosity) (Concer and Marcondes, 2017; Großmann and Wiemer, 2005; Walkington, 1997),

- testing different types of machining and chemical heat treatment on leak tightness of the casting mold, maintaining the correctness of geometrical dimensions and improvement of casted products exploitation properties.

- verification of linearity centering and collision between the movable parts and unmovable parts of the mold. 
- manufacturing parameters optimization of the large-size mold so that the casted component meets all the requirements and application properties in the operating conditions,
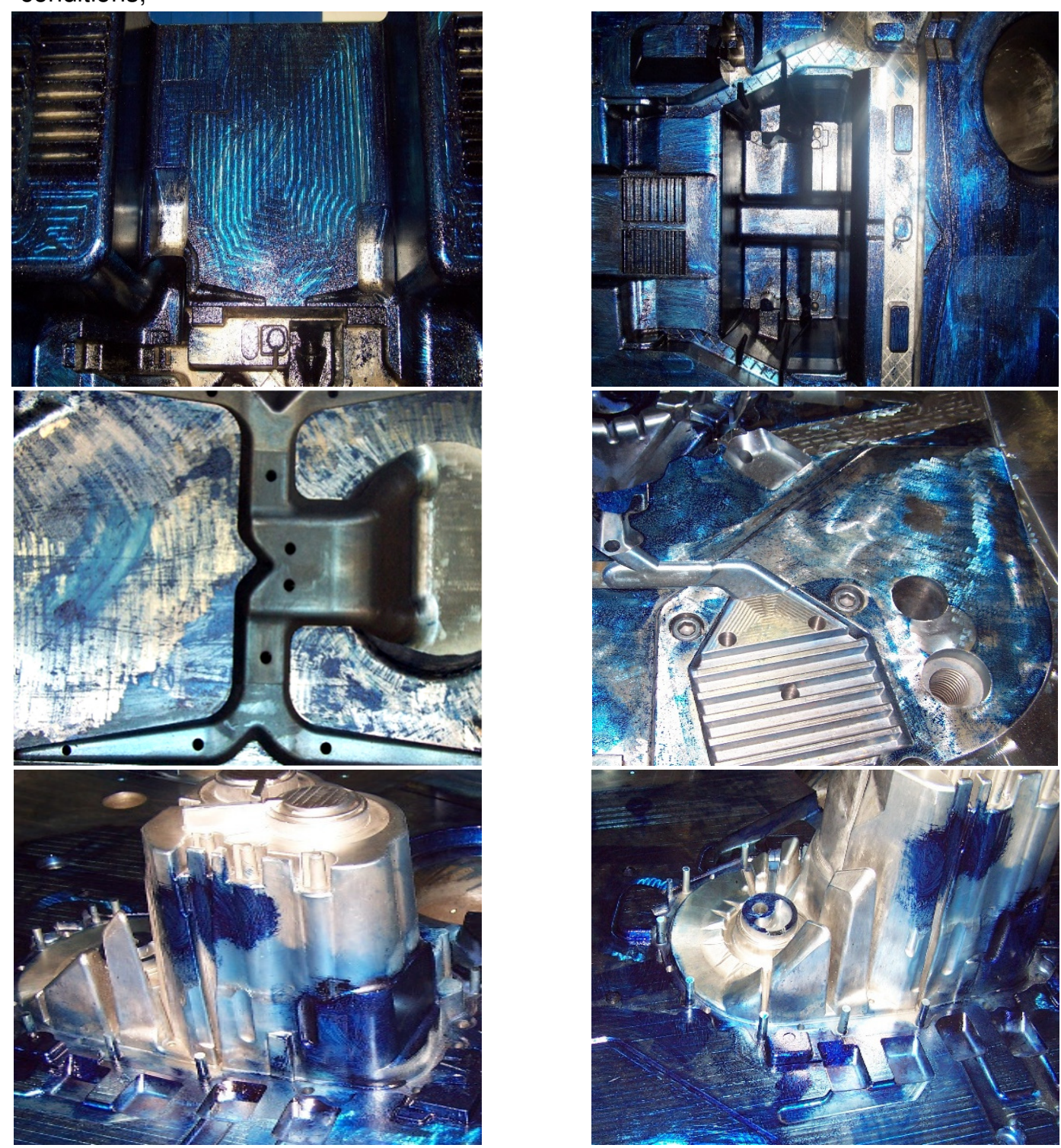

Fig. 3. View of the areas of the large-size molds subjected to dimensional correction directly on the spotting press

The die spotting press-machine implementation is an innovative solution in the field of the process innovation related to the performance of the die spotting function to improve the production effectiveness and quality control. Research realized in the R\&D department using the die spotting press machine mainly allowed for verifying the correctness of geometrical parameters of prototypes of large-size molds; checking leak tightness of large-size molds directly at future operating conditions (temperature, pressure, casting chemical composition) set for casting machines in the industrial units, testing the impact of the mold temperature and cast material injection pressure on leak tightness of the mold. The application of quality control process associated with the use of the die spotting press machine as well as the obtained results enabled for an improvement in the technology of single mold block and reduction in time of its manufacturing. A significant reduction in time of the correction of shapes and dimensions of the manufactured mold is particularly worth pinpointing as Key results of the implementation: 
- Key result $1 /$ Die spotting duration of the large size mold with the correction of dimensions and precise grinding process was 2 to 4 days,

- Key result 2/Complex mold manufacturing process time was up to 4 weeks,

- Key result $3 /$ Reduction in mold production time by approx. $40 \%$ (duration of production according to the existing technology was approximately 6-8 weeks).

- Key result 4/Production of a high-quality casting element, which is directly associated with ensuring leak tightness and precise linearity of the tooling components.

It might be concluded that the assumed result index concerning the shortening of production technology was achieved. At the same time, there were calculated the indices of Overall Equipment Effectiveness (OEE) of the new equipment. The OEE index is calculated by multiplying three factors: availability $A$, performance $P$ and quality $Q$. The index is estimated on the basis of the time of availability of the machine for work, its performance and the quality of manufactured elements. The results of OEE for mold and press-forming die spotting are presented in Table 1. (Oechsner et al., 2003)

Table 1.

OEE index for the die spotting press machine used for quality control process of large size molds

\begin{tabular}{|c|c|c|c|c|c|c|}
\hline Indices [\%] & $\mathbf{2 0 1 2}$ & $\mathbf{2 0 1 3}$ & $\mathbf{2 0 1 4}$ & $\mathbf{2 0 1 5}$ & $\mathbf{2 0 1 6}$ & $\mathbf{2 0 1 7}$ \\
\hline $\mathbf{A}$ & 89.3 & 90.2 & 91.0 & 90.3 & 90.5 & 91.6 \\
\hline $\mathbf{P}$ & 93.4 & 93.4 & 94.0 & 94.1 & 93.9 & 94.8 \\
\hline $\mathbf{Q}$ & 97.2 & 98.0 & 98.0 & 98.1 & 98.0 & 98.7 \\
\hline OEE & 81.07 & 82.56 & 83.82 & 83.35 & 83.28 & 85.70 \\
\hline
\end{tabular}

On the basis of the value of the OEE index it can be found that highest value was obtained in 2017 (85.70\%) while the lowest in 2012 (81.07\%), which results from the stage of the spotting process realization. The factors of availability, quality and performance confirmed that the innovative quality control positively affected both the quality of castings (increase by almost $4 \%$ in 2017 in relation to the first year of process implementation) and the optimization of the production cycle (an increase in the performance index to $2 \%$ in the research period). In compare to the period before the spotting press implementation (2007-2010), the OEE index increased on average by $5.4 \%$. In the research into innovativeness of the results of implementation - the modern press machine, one may refer to the functionality formula 1 . The author, adopting the interpretation of functionality as the satisfactory degree of implementation of functions in the system - in this case, the process innovation, presents the basic formulas and criteria for assessment in the above area. There is highlighted the cost of performing the function (KF), determined by the following formula (Stabryła, 2005):

$$
K F=\sum_{i=1}^{m} g_{i}+\sum_{k=1}^{n} y_{k}
$$

where:

$g_{i}-$ costs of extracted functions - innovativeness,

$y_{k}-$ costs of integrated functions - production.

In further considerations, this author indicates the possibility of calculating an increase in functionality - i.e. innovation and the cost of performing the function of the company, identified with the manufacture of products of increasing quality. As a result, with the implemented process of an increase in productive resources - the purchase of innovative equipment ensuring an increase in the quality of production, a new dimension of effectiveness of the company is achieved. In the assessment of effectiveness, there are compared the achieved results arising due to the implementation of innovative technologies to the expenditure associated with the purchase of modern equipment. An increase in the value of assets 
resulting from innovative processes have generally enabled an improvement in the financial results of the company. In the strategy of its operation there has been an improvement in the level of innovativeness, which will determine further directions of development based on detailed results of the project financed with the European Union funds. The purchased die spotting press machine for molds and press-forming dies, within the framework of the research of the R\&D department, prospective and implemented so far, allowed for introducing the input data into the mold project software, taking into account the use of cyclic spotting as one of the final stages of mold production. The purchase and possession of the die spotting press machine created the conditions, not used so far, for increasing operational durability of molds through the implementation of testing the correction of dimensions and shape also at the stage of inter-operational mold regeneration.

\section{CONCLUSIONS}

The purchase of the innovative device - die spotting press machine for quality control of the large-size molds for pressure die-casting of aluminum alloys, magnesium alloys etc. allowed to obtain results that are useful in terms of improving the production technology of large-size molds, as well as to implement prospective orders to manufacture molds weighing more than 10 tons. The study that was carried out aimed at the verification of the current technology of manufacturing large-size molds and the verification of the benefits of the process of spotting the mold at the stage of shape and dimension correction in terms of increasing the effectiveness of the mold making process. The applied spotting processes allowed for the correction and verification of material surpluses for the fixed and movable part of the mold directly on the press, as well as the introduction of necessary final corrections in areas of the mold construction, both to the design documentation and directly in the mold. The corrected areas of the mold, requiring special machining operations, have been indicated in the $\mathrm{CAD} / \mathrm{CAM}$ design documentation. It can be stated that the findings obtained from the research on the implementation of the spotting process of a multi-block large-size mold with the use of the spotting press have made it possible to perform the previously impossible operations of quick adjustment and correction of the mold straight after the test on the press. The time of the mold spotting process along with the dimensional correction and operations of finishing machining was about 2 to 3 days. Implementation of the stage of large-size mold spotting allowed for a considerable reduction of the entire time of implementing the technology to about 3 weeks from the date of order, where in case of earlier implementations of medium-sized molds this time was about 4 to 7 weeks. Therefore, it can be stated that the assumed key results has been achieved, which is indicated by the presented data of the OEE production coefficient. Implementation of innovative quality control technologies allowed to create the conditions for the development of a new operational strategy in the market of the metalworking industry with the opportunity to compete not only on the domestic market but also on the foreign one. Moreover, the standards of technological and qualitative product manufacture in the form of large-size molds were raised, which has a significant impact on obtaining new prospective markets of the metal sector, including the metalworking and foundry industry. An important aspect of having a press for die spotting is the introduction of the archiving of the data of die spotting technology, which is of great importance in the event of potential arbitrary disputes regarding possible premature wear of the mold, connected with, for example, the change of the shape and dimensions of the cooperating surfaces of the mold during its operation at the customer and the quality of the manufactured casts.

\section{REFERENCES}

Concer, D. and Marcondes, P. V. P. (2017). Experimental and numerical simulation study of porosity on high-pressure aluminum die casting process. Journal of the Brazilian Society of Mechanical Sciences and Engineering Vol.: 39 Issue: 8 pp. 3079-3088. 
Großmann, K. and Wiemer, H. (2005). Simulation of the Process Influencing Behaviour of Forming Machines. Steel Research International 76, No 2/3, Stahleisen GmbH Düsseldorf.

Haddag B., Nouari, M. and Moufki, A. (2016). Some cases of machining large-scale parts: characterization and modelling of heavy turning, deep drilling and broaching. AIP Conference Proc. 1716, pp. 1-9.

Hamrol, A. and Mantura, W. (2005). Quality Management. Theory and Practice, Warsaw: PWN Editors.

Hashikawa, Ryuichi \& Osada, Toshiko \& KUDO, Kentaro \& Tsumori, Fujio \& MIURA, Hideshi (2016. Control the Distortion of the Large and Complex Shaped Parts by the Metal Injection Molding Process. Journal of the Japan Society of Powder and Powder Metallurgy, Vol. 63. pp. 473-478.

Jurgen, S. and Uwe S. (1994). Finishing of dies and moulds An approach to quality-orientated automation with the help of industrial robots. Industrial Robot: An International Journal, Vol. 21 Issue: 1, pp.28-31.

Nowicka-Skowron, M. and Ulewicz, R. (2015). Quality management in logistics processes in metal branch. In: METAL 2015 - 24th International Conference on Metallurgy and Materials, Conference Proceedings. pp. 1707-1712.

Nunes, V., Silva, F. J. G., Andrade, M. P. et al. (2017). Increasing the lifespan of high-pressure die cast molds subjected to severe wear. Surface \& Coatings Technology Vol. 332, pp. 319-331

Lynch, P., Walsh, M. and Harrington, D. (2010). Defining and Dimensionalizing Organizational Innovativeness. International CHRIE Conference-Refereed Track, USA.

Łuszczak, M. and Dańko, R. (2013). Stan zagadnienia w zakresie odlewania dużych odlewów strukturalnych ze stopów aluminium. Archives of Foundry Engineering, Vol. 13, Nr 3, 113 -116.

Milutensil Company (2015). Lower mold-testing costs with spotting press, Moldmaker.

Skrzypek, K. and Dąbrowski, K. (2017). Using of integrated systems in Polish manufacturing enterprises from metal and automotive industry. Zarządzanie Przedsiębiorstwem, Zeszyt 2, p. 22 (in Polish).

Oechsner, R., Pfeffer, M., Pfitzner, L., Binder, H., Muller, E. and Vonderstrass T.(2003), From overall equipment efficiency (OEE) to overall Fab effectiveness (OFE). Materials Science in Semiconductor Processing 5.

Onozuka, H., Utsumi. K., Kato. T., Takahashi. H. and Obikawa. T. (2013). Optimal design of a damped arbor for heavy duty machining of giant parts. Journal of Advanced Mechanical Design, Systems, and Manufacturing, Vol. 7, pp. 171-186.

Sarmiento-Merida, L. A., Guevara-Morales, A. and Figueroa-Lopez, U. (2018). Determining the Optimum Parting Direction in Plastic Injection Molds Based on Minimizing Rough Machining Time during Mold Manufacturing. Advances in Polymer Technology, Vol. 37 Issue: 1.

Schöne, Christine \& Stelzer, Ralph \& Schmidt, Ulf \& Süße, Dietmar (2010). Reverse Engineering for Spotting of Sheet Metal Forming Parts.

Flavio M. and Josh, K. (2015). The Hidden Value of a Spotting Press As mold complexity increases, so, too, does the complexity of maintenance, which advances the role of spotting in mold validation.

Shimizu, T., Kitazima, A., Nose, M., Fuchizawa, S. and Sano, T. (2001). Production of large size parts by MIM process. Journal of Materials Processing Technology, 119 (1-3), pp. 199-202.

Skotnicka-Zasadzien, B., Wolniak, R. and Zasadzien, M. (2017). Use of quality engineering tools and methods for the analysis of production processes - case study. Proceedings of the $2^{\text {nd }}$ International Conference on Economic and Business Management Book Series: AEBMRAdvances in Economics Business and Management Research Vol. 33, pp. 240-245.

Stabryła, A. (2005). Categorization as an Instrument in Managing Company Development Capacity. Argumenta Oeconomica Cracoviensia, No 3.

The "invisible" sector of European industry - now in the center of attention. Metalworking and production of metal products, European Commission, 2010 (in Polish).

Walkington, W.G. (1997). "Die Casting Defects. Causes and solutions". North American, Die Casting Association, Illinois U.S.A.

Stasiak-Betlejewska, R., Ulewicz, R., (2016). The effectiveness of selected machinery and equipment in the woodworking joinery, in: The Path Forward for Wood Products: A Global Perspective Proceedings of Scientific Papers. pp. 149-156.

Zasadzien M., Midor K (2015), Innovative Application of Quality Management Tools in a Hard Coal Mine, Science And Technologies in Geology, Exploration And Mining, Vol. III, pp. 415-422.

Zorawski, W., Chatys, R. Radek, N. et al. (2008), Plasma-sprayed composite coatings with reduced friction coefficient. Surface \& Coatings Technology Vol. 202 Issue: 18, pp. 4578-4582. 